\title{
A multimodal pathway including the basal ganglia in the feline brain
}

\author{
G Benedek ${ }^{1}$, S Keri ${ }^{1,2}$, A Nagy', G Braunitzer ${ }^{3}$, M Norita ${ }^{3}$ \\ ${ }^{1}$ Department of Physiology, University of Szeged, Szeged, Hungary \\ ${ }^{2}$ Nyirő Gyula Hospital, Laboratory for Perception \& Cognition and Clinical Neuroscience, Budapest, Hungary \\ ${ }^{3}$ Department of Anatomy, Niigata University, Niigata, Japan
}

Received: May 2, 2018

Accepted: April 1, 2019

\begin{abstract}
The purpose of this paper is to give an overview of our present knowledge about the feline tecto-thalamo-basal ganglia cortical sensory pathway. We reviewed morphological and electrophysiological studies of the cortical areas, located in ventral bank of the anterior ectosylvian sulcus as well as the region of the insular cortex, the suprageniculate nucleus of the thalamus, caudate nucleus, and the substantia nigra. Microelectrode studies revealed common receptive field properties in all these structures. The receptive fields were extremely large and multisensory, with pronounced sensitivity to motion of visual stimuli. They often demonstrated directional and velocity selectivity. Preference for small visual stimuli was also a frequent finding. However, orientation sensitivity was absent. It became obvious that the structures of the investigated sensory loop exhibit a unique kind of information processing, not found anywhere else in the feline visual system.
\end{abstract}

Keywords: basal ganglia, anterior ectosylvian visual area, insular cortex, suprageniculate nucleus, caudate nucleus, substantia nigra

\section{Introduction}

In the 1960 s and early 1970 s of the past century, it seemed that basal ganglia served primarily to integrate diverse inputs from the entire cortex and to funnel these inputs via the ventrolateral thalamus to the motor cortex (47). Alexander et al. $(2,3)$ were the first to describe parallelly arranged, closed-loop components of neocortical connections with the basal ganglia and related thalamic nuclei. It was shown that the same thalamic nuclei received direct projections from the superior colliculi (51). McHaffie et al. (64) proposed that a phylogenetically older, closed-loop series of subcortical connections exist between the basal ganglia and brainstem sensorimotor structures, a good example of which is the midbrain superior colliculus. They found at least three functionally segregated systems, one originating from the superficial layers and two from the deep layers. Our research group conducted several studies to investigate the multisensory receptive field properties of various components of this system, with an emphasis on the visual modality $(6,11,73-76)$. We managed to

Corresponding author: Prof. György Benedek, MD, PhD

Department of Physiology, University of Szeged

Dóm tér 10, Szeged 6720, Hungary

Phone: +36 62545 098; Fax: +36 62545 842; E-mail: benedek.gyorgy@med.u-szeged.hu

This is an open-access article distributed under the terms of the Creative Commons Attribution 4.0 International License, which permits unrestricted use, distribution, and reproduction in any medium, provided the original author and source are credited, a link to the CC License is provided, and changes - if any - are indicated. (SID_1) 
identify both cortical and thalamic areas as parts of this system and described their visual properties. It turned out that the visual properties of these structures are unique and not observable in any other part of the visual system.

\section{The pattern of the pathways connected colliculus with cerebral cortex, thalamus, and basal ganglia}

The central element in this pathway is the superior colliculus. The pathway is a closed loop, in which the superior colliculus accumulates the sensory information and gives rise to important descending and ascending pathways. The superior colliculus is a multilayered structure of the mammalian mesencephalon. It collects information directly from the sensory cortex and indirectly through the basal ganglia. Its cortical afferents arrive from almost the entire cortex including the banks of the anterior ectosylvian sulcus (AES). The major ascending output is directed to the extrageniculate visual thalamus [the lateral posterior nucleus, the suprageniculate nucleus (SG), and the pulvinar] $(1,9,13)$. This thalamic region, in addition to its connections with the extrastriate visual cortex $(29,87,109)$, also projects extensively to head and tail of the caudate nucleus $(\mathrm{CN})$ and dorsolateral putamen $(33,55$, $96,104)$. The next segment of the loop is the "direct" striatonigral pathway to lateral parts of the substantia nigra $(\mathrm{SN})$.

In addition to their descending projections of the superior colliculus to the pons and to the medulla, both the superficial and the deep layers of this structure also have ascending connections to targets in the thalamus, including the lateral posterior nucleus and the midline intralaminar nuclear complex $(51,55)$. It is noteworthy that the ascending projections from the superior colliculus specifically target regions of the thalamus that provide the major thalamic input to the two principal input structures of the basal ganglia $(23,25,104)$. In the following, we describe this loop containing the superior colliculus, the multisensory parts of the thalamus, first of all the SG, the cortical structures along the AES, and the SN pars reticulata $(\mathrm{SNr})$ as well as the $\mathrm{CN}$.

\section{Anterior ectosylvian visual area}

The role of the anterior ectosylvian cortex in visual information processing was first indicated by evoked potential studies $(15,18,30)$. We first described a visual area situated in the cortex surrounding the deep infolding of the cat $(73)$. Other investigators $(81,97)$ confirmed our description. Clarey and Irvine $(21,22)$ described an auditory area along the AES. Later, a neighboring insular visual area was also found $(6,7,35,36,110)$, which overlaps with the insular auditory area (101) and appears to be a multimodal area. Similar area was described by Linke and Schwegler (56) in rats, by Malinowska and Kosmal (60) in dogs, and by Manger et al. (61) in ferrets.

Studies exploring the ventral banks of the anterior ectosylvian cortex revealed that there are visually sensitive cells along the whole extent of the sulcus (7). In Fig. 1, response curves for $2^{\circ}$ spot stimulation of eight anterior ectosylvian visual area (AEV) neuron (1) and effect of length of stimulus on the response of these neurons (2) are demonstrated. AEV (73) was found to be dominated by neurons sensitive to very small stimuli moving rapidly in huge receptive fields that cover practically the whole visual field of the eye (Fig. 2). These neurons are also characterized by very high directional sensitivity.

The connections between AEV and other cortical areas are reciprocal. Subcortically, AEV has reciprocal connections with the ventral medial thalamic nucleus (vertical meridian), with the medial part of the lateralis posterior nucleus, as well as with the lateral medial-SG 
A

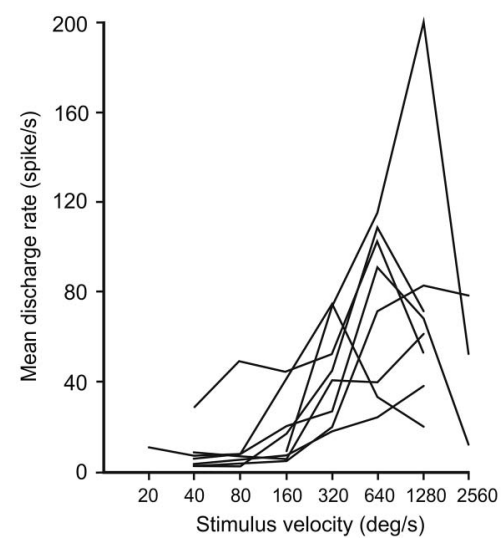

B

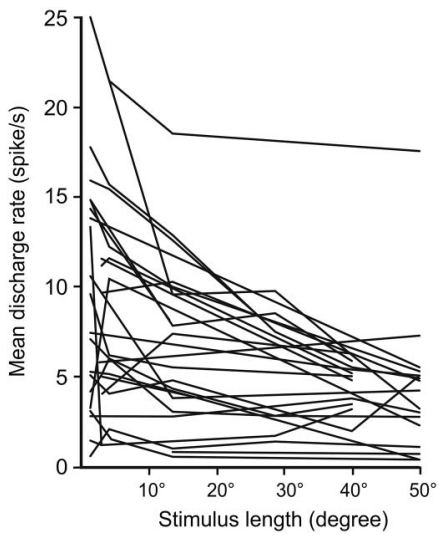

Fig. 1. (A) Response curves for spot stimulus ( $2^{\circ}$ in diameter) of eight AEV visual neurons. (B) Effect of length on the response of $\mathrm{AEV}$ visual neurons

complex. AEV also projects to the $\mathrm{CN}$, the putamen, the lateral amygdaloid nucleus, the superior colliculus, and the pontine nuclei (80).

\section{The SG: Location and nomenclature}

Retrograde tracing studies showed strong connections between AEV and the SG (80). This initiated our studies which proved that this thalamic structure is the chain between superior colliculus and AEV/insular cortex $(6,7,79)$.

The SG was identified in cats quite early $(43,90)$. Its existence has been described in a wide range of mammals including rats (58), rabbits (93), dogs (108), and monkeys (82). The feline SG is composed of loose clusters of cells dorsomedial to the magnocellular part of the medial geniculate body $(92,94)$ (Fig. 3). The SG and caudal LP of the cats receive afferents from the SC, the nucleus of brachium of the inferior colliculus, the spinal cord (104), the spinal trigeminal nuclei (12), and the cuneate nucleus (32). It contains neurons responding to visual $(19,27,37,63,103)$ and multimodal stimuli $(12,19)$.

\section{Physiology of the SG}

The early physiological studies found overwhelmingly auditory representation in SG, but its multimodal characteristics were soon discovered $(12,94)$. Poggio and Mountcastle (85), however, considered the nucleus as a nociceptive thalamic structure, paying only little attention to other sensory aspects. Visual properties were not mentioned by these authors at all, while other groups seem to have found visual units only occasionally in this nucleus $(27,42,63)$. Studies to call attention to the visual properties of the cells in SG appeared only a decade later $(37,53)$. Example of directional selective visual neurons in SG is given in Fig. 4. New perspective for the investigation of the SG was opened after the description of unimodal visual, auditory, and multisensory areas extending over the ventral bank of the AES, and on the surface of the anterior sylvian gyrus $(21,22,48,71,73,81,105)$. The idea emerged that the SG might serve as a relay station between the intermediate and deep layers of the colliculus superior and these cortical areas $(5,10,35,36)$.

\section{Internal connectional pattern of the basal ganglia}

The important elements of the functional system, discussed in this review, are structures of basal ganglia. The basal ganglia contain two principal input parts: the neostriatum 

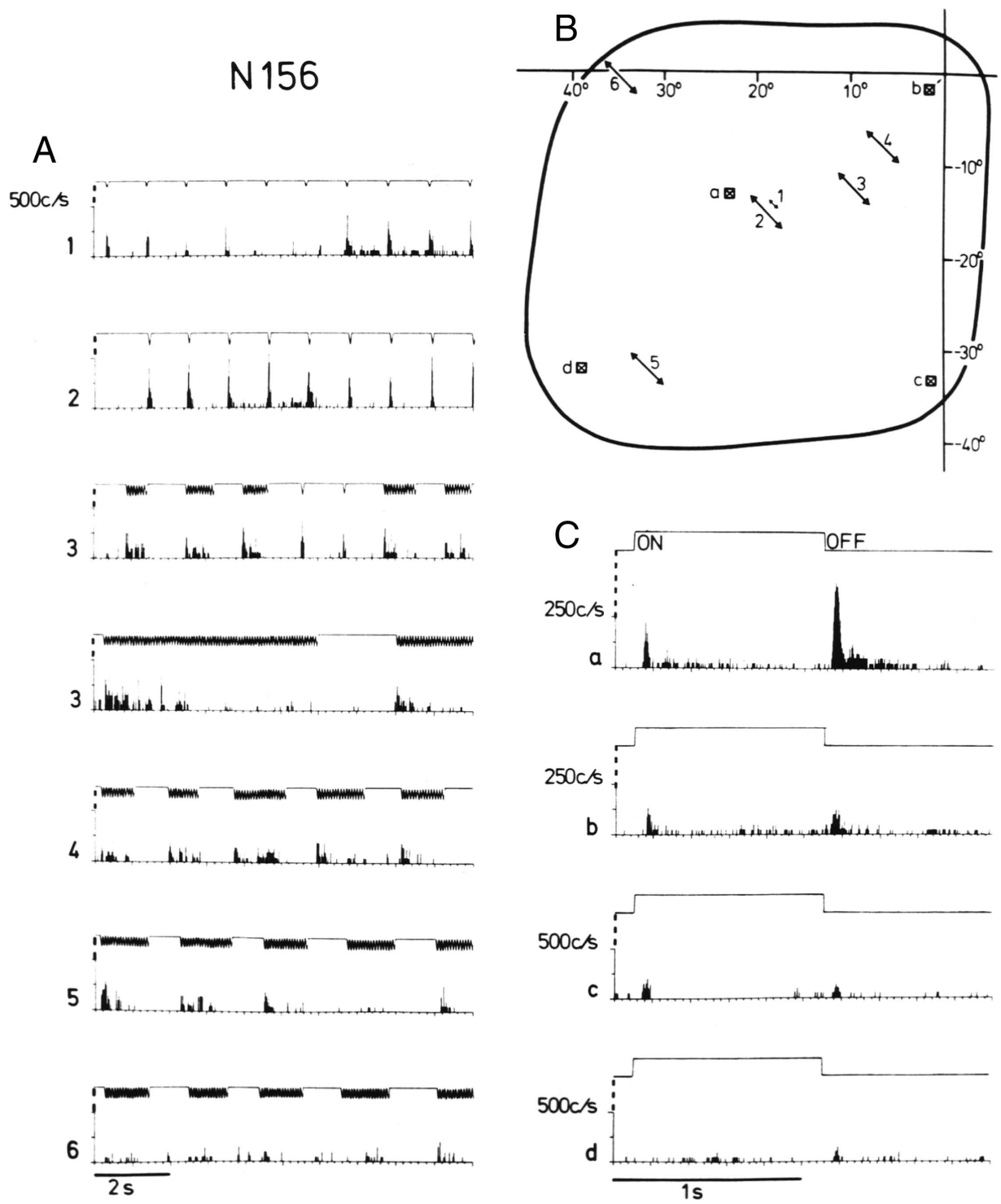

Fig. 2. Responses to small amplitude stimulation (A) and on-off stimulation (C) in different parts of the receptive field (B) of neuron 156 (contralateral eye stimulation). The center of the coordinate system in (B) corresponds to the left area centralis, and the abscissa and ordinate represent the horizontal and vertical meridia, respectively. The moving stimuli in (A) and (B) were light spots $1.6^{\circ}$ in diameter that swept at a speed of $500^{\circ} / \mathrm{s}(\mathrm{A} 2-6)$ through parts of the receptive field. For stationary stimuli, a light square measuring $1.5^{\circ} \times 1.5^{\circ}$ was turned on and off at 1 -s intervals. Arrows 1-6 in (B) indicate the position, amplitude, and direction of the stimulus sweeps yielding the corresponding peristimulus time histograms (PSTHs) in (A). Squares a-d in (B) represent the position of the stationary stimulus and refer to the respective PSTHs in (C). The analog signal above each histogram represents the stimulus movements (A) and closing of the shutter for on-off stimulation (C), respectively. PSTHs in (A) show neuronal responses to single stimulus sweeps. However, the trains of forward/backward stimulus movements were also applied. The PSTHs in (C) give summed responses obtained from 20 successive stimulus presentations 

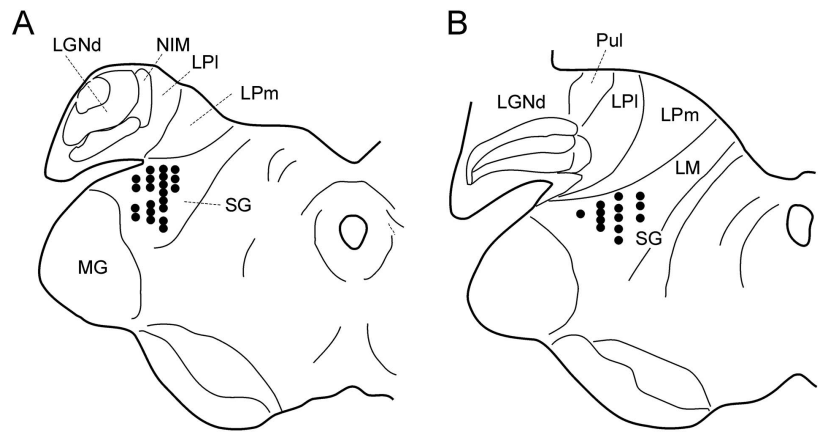

C

Fig. 3. Schematic (A and B) and histological (C) illustration of SG

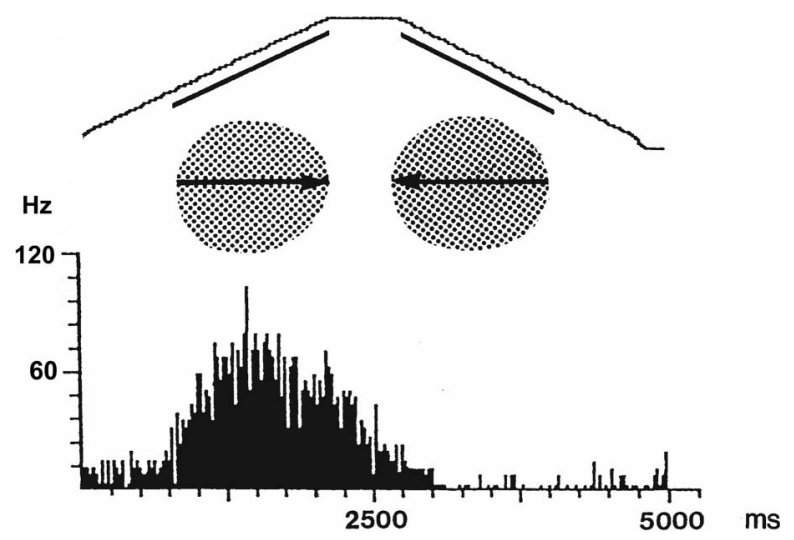

Fig. 4. Peristimulus time histograms (PSTHs) of a tonically firing SG neuron to moving light spot. Shaded areas illustrate the receptive field and the arrows in it the direction of spot movement. Trajectory of the light stimulus movement is shown on the top of the figure. Abscissa time (ms) in an ordinate shows the firing rate during 20 trials

(including $\mathrm{CN}$ and putamen) and the subthalamic nucleus (STN), and two principal output nuclei: the $\mathrm{SNr}$ and the entopeduncular nucleus (globus pallidus pars interna). The dopaminergic neurons of the $\mathrm{SN}$ (pars compacta, $\mathrm{SNc}$ ) project to the neostriatum (nigro-striatal dopaminergic pathway), and SNc receives afferents principally from the striatum (striatonigral GABAergic pathway). The basal ganglia receive inputs predominatly from the cerebral cortex; however, subcortical (thalamic) inputs also exist. Cortical and thalamic efferent information enters the striatum to be processed further within the system of the basal ganglia. Although extrathalamic connections can also be observed, the output nuclei mainly project to the thalamus, which, in turn, projects back to the cerebral cortex.

\section{Basal ganglia connections with structures involved in analysis of visual information}

Pouderoux and Freton (86) were the first to report visual responses in the feline CN. Morphological findings on cats and rabbits have demonstrated that the corticostriatal pathways send sensory information to the $\mathrm{CN}(41,79,111)$. The dorsolateral part of the $\mathrm{CN}$ in the cats may receive its visual afferentation from the tectum via the SG of the thalamus $(34,75)$. The excitatory visual inputs of the SN (note that since the overwhelming majority of neurons collected by us were in the $\mathrm{SNr}$, in the following, we pool our data under the name substantia nigra SG) may originate from the $\mathrm{CN}$ (91) and from direct or indirect tectal pathways through the $\operatorname{STN}(45,49,107)$ and the pedunculopontine tegmental nucleus $(57,89)$. 
Multisensory sensitivity of neurons in the pathway

The neurons in basal ganglia exhibit characteristic receptive field properties, as evidenced by the results obtained in our $(8,73-76)$ and other $(20,37,64,81,99,102)$ studies (Fig. 5). In our studies, we identified visual, auditory, and somatosensory sensitivities in unimodal, bimodal, or trimodal neurons. It is an interesting characteristic of the neurons in this tecto-thalamo-cortico-thalamo-basal ganglia pathway that their sensitivity is not confined to one sensory modality. Such multimodality was reported also in connection with the neurons in the intermediate and deeper layers of the superior colliculus $(100)$, the $\operatorname{SG}(5,10)$, the cerebral cortex along the AES, the AEV, and the insular visual area $(6,7,35)$. Examples of two such neurons are given in Figs 5 and 6. Although the neurons of this pathway often were multimodal, the visual modality was found to be dominant and the visual-receptive fields of these neurons were extremely large. Much less neurons show only auditory or somatosensory preferences (Table I). It is an interesting property of this pathway that there is an interaction between the different modalities $(11,46,76)$ (Fig. 6).

\section{Comparison of Receptive Field Properties in the Structures of the Pathway: Length, Velocity, and Directional Sensitivity}

In this section, we try to compare the length, velocity, and directional sensitivity of neurons recorded in different parts of the loop. The data were recorded from the studies of Benedek et al. $(5,10)$, Mucke et al. (73) Hicks et al. (36), and Nagy et al. $(74,75)$.

\section{Length sensitivity}

Length sensitiviy of neurons means that the cells were stimulated by bars of different lengths moving orthogonally to the axis in front of the cat's eye and the responses were compared

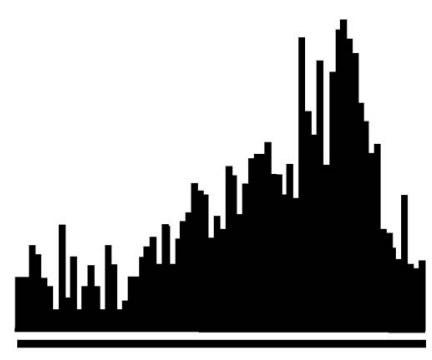

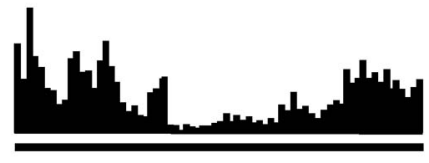

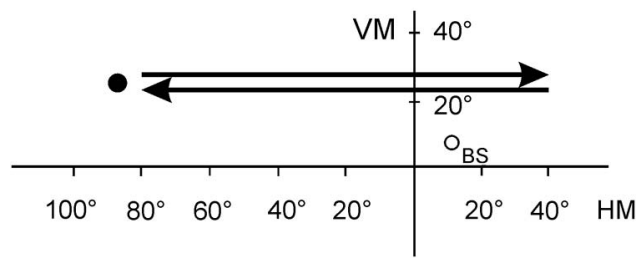

Fig. 5. Peristimulus time histograms (PSTHs) demonstrating a direction-selective caudate single unit. The thick lines under the PSTHs represent the duration of the stimulus movement (peristimulus time). The position and movement of the stimulus in the visual field of the cat are depicted in the bottom. Coordinates are given in degrees. The black spot left to the arrows symbolizes the moving visual stimulus.

The upper and lower PSTHs correspond to 20 responses of the neuron to the stimulus moving along the trace indicated by the upper and lower arrows, respectively. VM: vertical meridian; HM: horizontal meridian; BS: blind spot 

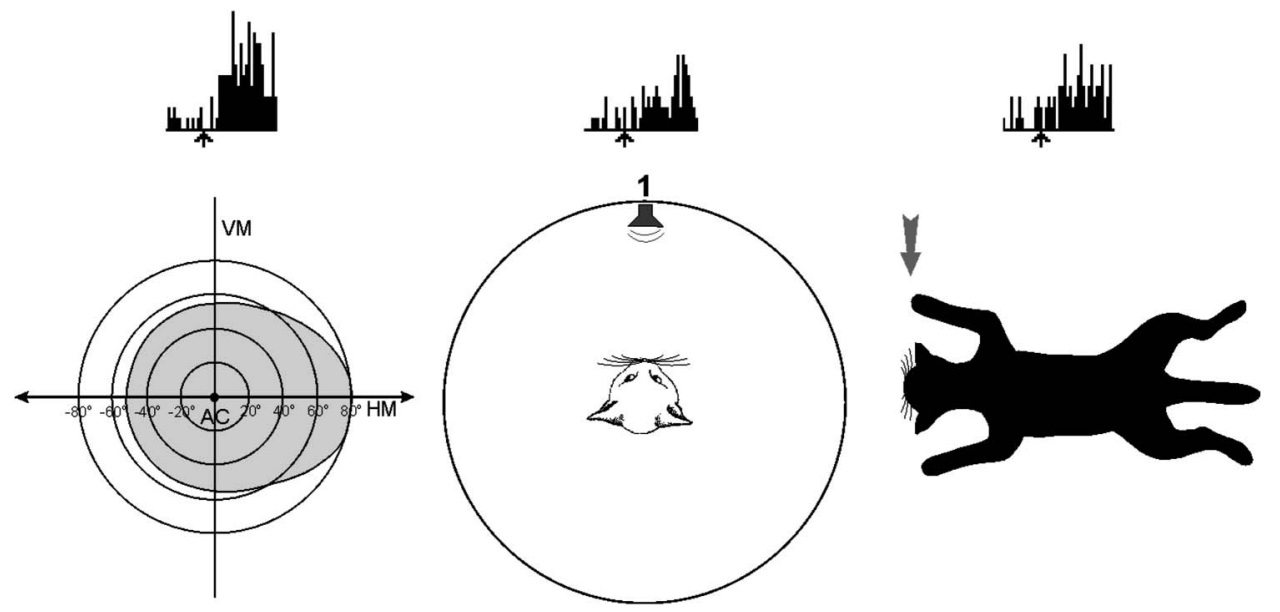

Fig. 6. Responses of a trimodal caudate neuron to visual (left), auditory (middle), and somatosensory (right) stimulation. Below the extents of the visual receptive fields and the sites of stimulation are indicated. The PSTHs show the single-unit activities before and during stimulation. Time of stimulation is shown by thick black arrows

Table I. Number and proportion of unimodal, bimodal, and trimodal neurons in the studied structures

\begin{tabular}{|l|l|c|c|c|c|c|l|l|}
\hline \multirow{2}{*}{} & \multirow{2}{*}{ Sum } & \multicolumn{4}{|c|}{ Unimodal } & \multicolumn{3}{c|}{ Bimodal } \\
\cline { 3 - 9 } & & V & A & S & VA & VS & \multicolumn{1}{c|}{ AS } & Trimodal \\
\hline Ins/AEV & 111 & $50(45 \%)$ & $16(14 \%)$ & $12(11 \%)$ & $11(10 \%)$ & $11(10 \%)$ & $25(23 \%)$ & $10(9 \%)$ \\
\hline SG & 109 & $74(68 \%)$ & $12(11 \%)$ & $23(21 \%)$ & $8(7 \%)$ & $14(13 \%)$ & $1(0.9 \%)$ & $13(12 \%)$ \\
\hline CN & 111 & $30(27 \%)$ & $9(8 \%)$ & $31(28 \%)$ & $10(9 \%)$ & $5(5 \%)$ & $18(16 \%)$ & $8(7 \%)$ \\
\hline SN & 124 & $52(42 \%)$ & $6(5 \%)$ & $12(10 \%)$ & $4(3 \%)$ & $16(13 \%)$ & $5(4 \%)$ & $9(7 \%)$ \\
\hline
\end{tabular}

The number of neurons is shown in the column "sum," then the number and proportion of unimodal, bimodal, and trimodal neurons are depicted. V: visual; A: auditory; S: somatosensory neurons; AEV: anterior ectosylvian visual area; SG: suprageniculate nucleus; SN: substantia nigra; $\mathrm{CN}$ : caudate nucleus

according to the lengths of the stimuli. In all studied structures, the majority of the visually sensitive cells responded vigorously to the small stimuli (most notably spots of $1^{\circ}$ in diameter), whereas longer bar stimuli $\left(3^{\circ}, 5^{\circ}, 10^{\circ}\right.$, and $\left.30^{\circ}\right)$ evoked less intensive responses. However, some cells showed the phenomenon of length summation; they responded with increased intensity to increasing stimulus length. Only a negligible proportion of cells were not sensitive to stimulus size. Proportions of responsiveness in each structure are shown in Fig. 7.

\section{Velocity sensitivity}

The neurons in each structure of this cortico-thalamo-basal ganglia-cortical system showed an overall sensitivity to moving objects. The preferred speed of the neurons was much higher than in A17 and exceeded even the high-velocity sensitivity values of A18, A19, or the visual areas around the suprasylvian sulcus (72). 


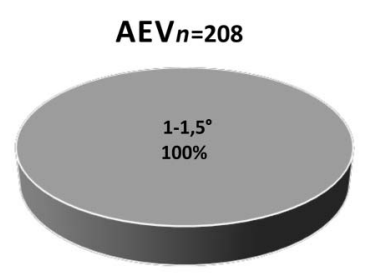

SG $n=103$

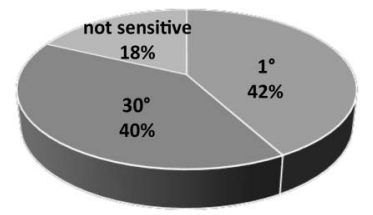

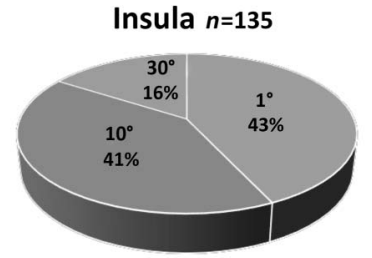

SN $n=59$

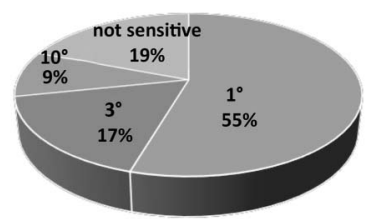

Fig. 7. Sensitivity of neurons to the length of stimulating light bars in the structures described in the review. The proportion of neurons most sensitive to different lengths of the stimulating bars (bar width was uniformly $1^{\circ}-1.5^{\circ}$ ) are given as pie chart presentations. SN means the pooled data from neurons in both $\mathrm{SNr}$ and $\mathrm{SNc}$, $n$ means the number of cells investigated in the given structure

The velocities tested covered a wide range between $10 \%$ s and $1000 \%$ s. Most of the cells responded to all the velocities tested, although we found cells that preferred a specific velocity range. Most of the cells tested responded most vigorously to high velocities $\left(60^{\circ} / \mathrm{s}\right.$ and above). A substantial proportion (approximately 20\%) of the AEV neurons responded even to stimuli moving at a speed of $640 \% \mathrm{~s}(8,45)$. No other area of the feline cortex contains such a high proportion of neurons responding to very fast stimuli. None of the $\mathrm{CN}$ units showed optimal responsiveness to the lowest examined velocity $(15 \%)(74)$. The summarized results of examination of velocity preference in all structures studied in our experiments are given in Fig. 8.

\section{Directional sensitivity}

The visually sensitive neurons in the tectum-related structures preferred moving stimuli, and neurons along the entire pathway exhibited rather strict directional sensitivity. Directionally sensitive neurons were detected in the superficial as well as in the intermediate and deep layers of the superior colliculus. The directional tuning of the neurons in the structures described in our studies appeared to be rather narrow $(5,10,36,73-75)$ (Fig. 9). We found that neuronal responses of AEV neurons were independent of stimulus shape: responses to a moving bar or a round spot could not be distinguished from responses to moving visual noise.

\section{Receptive field size}

It is common in the geniculostriate system that receptive fields are small $\left(1^{\circ}-2^{\circ}\right)$ and partly overlapping. Therefore, it was surprising that, in AEV, we observed huge receptive fields without retinotopic organization. Later, we found similarly huge receptive fields in the insular visual area $(6,7,36)$, the $\operatorname{SG}(5,10)$, the $\mathrm{CN}(74,75)$, and the $\mathrm{SN}(75)$. 


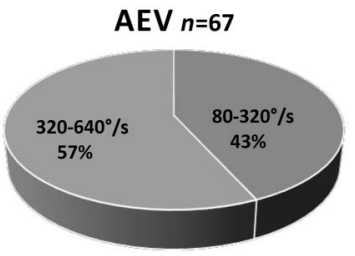

SG $n=113$
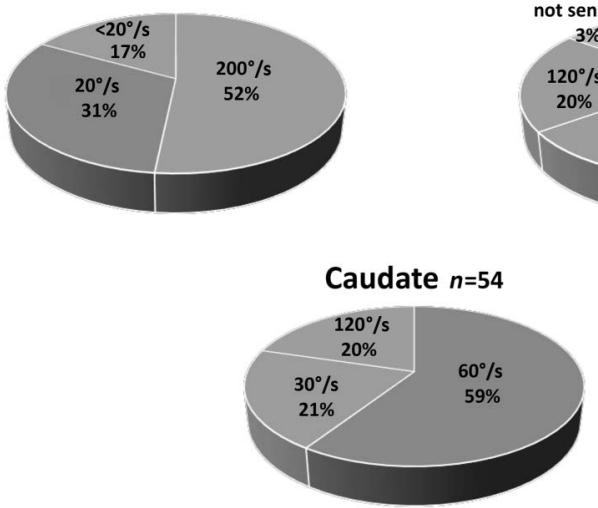
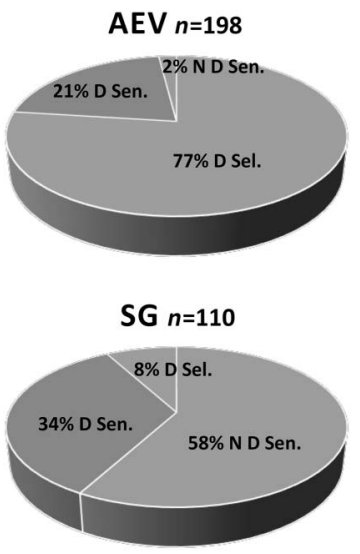

\section{Insula $n=104$}

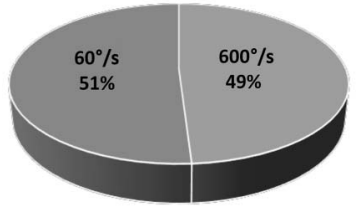

SN $n=59$

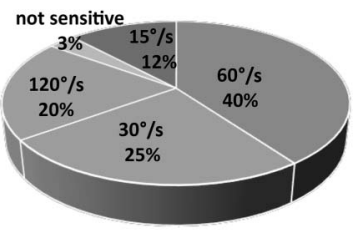

Fig. 8. Sensitivity of neurons to the velocity of stimulating light bars in the structures described in the review. The proportion of neurons most sensitive to different velocities given in degree/s values is given as a pie chart presentation. For the rest of explanations, see Fig. 7

Fig. 9. Direction sensitivity of neurons in the structures described in the review. The proportion of neurons most sensitive to different directions is given as a pie chart presentation. Direction sensitivity is classified as the proportion of velocity sensitive in the preferred vs. nonpreffered direction. DSI $=90 \%-100 \%$, directionally selective (DSel), DSI $=50 \%-90 \%$; directionally sensitive (DSen), DSI $\geq 50 \%$; non-directionally sensitive (NDSen), DSI $\leq 50 \%$. For the rest of explanations, see Fig. 7

The receptive fields of the neurons in the superior colliculus have been intensively investigated during the past 40 years (100). Clear retinotopic organization has been described for all layers. Single units in the superficial layers had relatively small receptive fields. 
The deeper a neuron was located in the superior colliculus, the larger was its receptive field. In the deep layers, the size of the visual receptive fields could be very large, that is up to $20^{\circ}$. Simultaneously in the AEV, Olson and Graybiel (81) found signs of retinotopic organization. We found that the receptive fields of the neurons along the pathway covered the entire visual field of the eye (73).

To support this claim, we applied brief visual stimuli in random locations in the entire visual field. We found no silent locations. This was followed by the selective stimulation of the area centralis, and inversely, the visual field except for the area covered by the area centralis. Finally, we performed a systematic analysis of the responses elicited in every part of the receptive field (36), which revealed that the receptive fields in these structures indeed covered the whole visual field of the stimulated eye. However, the position of the visual stimulus within the huge receptive fields could strongly influence the discharge rate of the single neurons. For every neuron in a huge receptive field, it was always possible to find the best area stimulation that evoked maximal firing rate. The best area locations were predominantly distributed within $40^{\circ}$ around the area centralis. The firing rate declined monotonously with shift of stimulus toward the periphery of the receptive field. Such receptive field organization potentially allows stimulus localization, in spite of their immense receptive field sizes.

\section{Stimulus Localization in the Ascending Tectofugal System: Panoramic Localizers and the Connected Distributed Population Coding}

The panoramic coding ability of single neurons has not been extensively studied, although a number of studies have quantified the spatial information carried by populations of panoramic cortical neurons $(54,88)$. Panoramic coding means that in different parts of the receptive field of a neuron, different levels of excitation respond to stimuli coming from different locations. This applies to both auditory and visual neurons.

Neurophysiological studies on the optic tectum in birds demonstrated that single auditory neurons provide information on the site of the stimulus source within their large receptive field and this location coincides with retinotopic map of visual neurons in superficial tectal layers (50). Such panoramic localizers were later described in invertebrates $(14,77)$ in visually guided behaviors of crabs $(65)$, owls $(50)$, and in the mammalian superior colliculus $(44,67)$.

Not much data have accumulated, however, on the existence of such a panoramic code in the mammalian cortex. Middlebrooks et al. (67-70) provided evidence of the panoramic localizing ability of neurons in the non-tonotopic auditory cortex along the AES of the feline brain. The AES neurons seem to have the potential to encode sound location within their huge receptive field throughout $360^{\circ}$ of azimuth. The accurate source localization is enabled by the distribution of information among a large population of such panoramic neurons $(17,69)$. Our studies revealed that visual neurons in the AES and in SG have similar panoramic abilities (Fig. 10) [The figure was obtained from Eördegh et al. (24)]. Direction of stimulation could be coded through panoramic coding in the acoustic cortex of cats (17), similar to the coding of the direction of movements in the motor cortex of primates (26). It has been published that ensembles of broadly tuned neurons, located in three distinct areas of the primate somatosensory cortex, obtain information about the location of a tactile stimulus almost concurrently (78). 
A

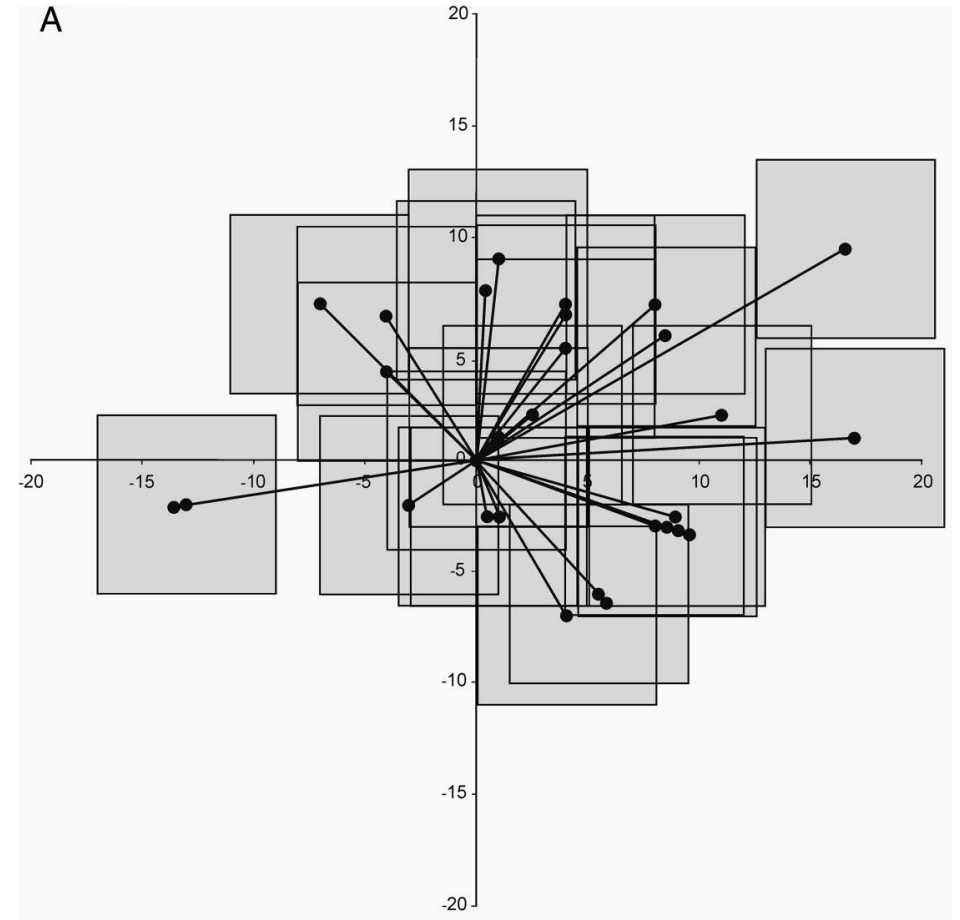

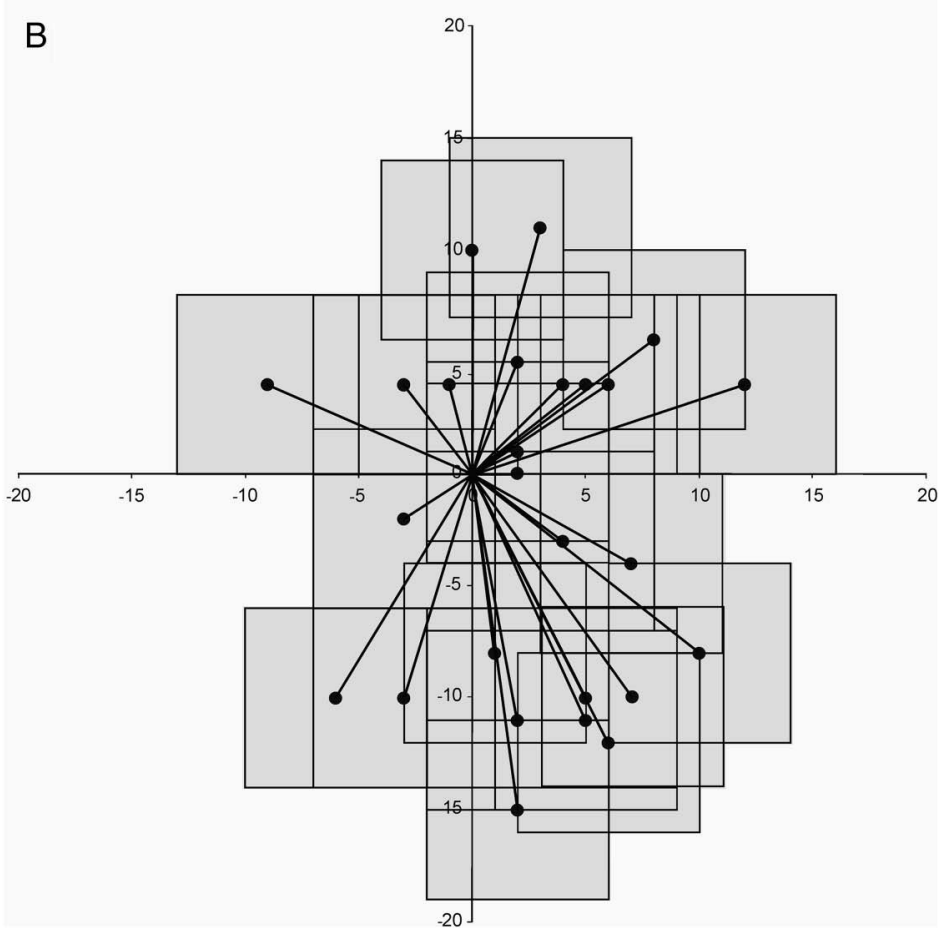

Fig. 10. Positions of the sites of maximum responsiveness in the receptive fields of visually responsive 32 AEV single units (A) and 35 SG single units (B) determined by the highest firing rate in the respective window [from (24)]. Every single unit is represented by an $8^{\circ} \times 8^{\circ}$ window representing the motion of the visual noise and a vector line between the area centralis and the center of the "window" from where the highest activity was elicited. Vertical and horizontal meridians are presented as thick lines, with scaling given in degrees 
The visual cortical area along the AES was explored systematically first by Mucke et al. (73) and Olson and Graybiel (81). Interestingly enough, the two groups described entirely differing receptive field arrangements. Olson and Graybiel (81) found moderately small receptive fields that followed a rather strict retinotopic arrangement, while Mucke et al. (73) and the later publications of our group described extremely large receptive fields that homogenously extended over the entire contra- and ipsilateral visual field of the respective eye. Similarly contradicting findings were published regarding the receptive fields in the SG. Krupa et al. (53) found large receptive fields (greater than $20^{\circ}$ ) and no retinotopic arrangement. For half of the cells, the receptive fields extended into both the contralateral and the ipsilateral fields of vision. On the other hand, Hicks et al. (37) found relatively small receptive fields in a rather well-organized retinotopic arrangement. The detailed study on the organization of receptive fields of neurons of the SG by Benedek et al. $(5,10)$ indicated that the visually responsive neurons of the SG had uniform, huge receptive fields that covered practically the entire visual field of the respective eye.

The classical visual receptive field properties of the caudate neurons (74) make them very similar to the neurons of the ascending tectofugal system $(62,83,84)$. The visual neurons in the $\mathrm{CN}$ have extremely large visual receptive fields that consistently include the area centralis and cover almost the entire visual field of the contralateral eye $(74,86)$. The large size of the receptive fields raised the question whether they were homogenous or comprised of functionally differing parts.

We attempted to verify the existence of panoramic coding in three ways. In the first experiments, we stimulated the receptive fields of neurons in the cat's AEV using visual stimuli with subsequent lighting of 12 light-emitting diode pairs at $15^{\circ}-15^{\circ}$ distance on the $165^{\circ}$ perimeter of the interaural plane. We found visual responsiveness of the single neurons varying according to the sites in the visual field (12). Later, we investigated the responsiveness of the single neurons to visual information arriving from different sites of the entire receptive field. We divided the whole visual field of the investigated eye to 20 parts of equal sizes and stimulated the individual parts one-by-one (11). We found that each single visual neuron could carry information about stimulus locations throughout the whole physically approachable visual field of the investigated eye. These neurons exhibited significantly different responses to stimuli appearing in different regions of their huge receptive field (24). Thus, these neurons appear to have the ability to provide information on the site of the stimulus via their discharge rate. The huge receptive fields in combination with the spatial selectivity suggest that these neurons may serve as panoramic localizers. At the population level, the sites of maximal responsiveness are not confined to any specific area of the visual field. We argue that groups of these panoramic localizer neurons with different locations of maximal stimulus preference should have the ability to accurately code the locations of visual stimuli.

As for the auditory neurons, they were consistently binaural with extremely large receptive fields. Similar to the visual neurons, the sites of maximal responsiveness of the auditory and bimodal neurons were distributed over the whole extent of the large receptive fields. Thus, a large population of such panoramic visual, auditory, and multisensory neurons could accurately code the locations of the sensory stimuli. Our findings support the notion that there is a distributed population code of multisensory information in the feline associative cortex $(4,11,28)$. 


\section{Discussion}

One of the most impressive features of the central nervous system is its ability to process information from a variety of stimuli to produce an integrated, comprehensive representation of the external world. This function is served by the integration of specific sensory channels developed to analyze signals from the individual sensory organs. In this review, we concentrated on the visual properties of the neurons in a specific multimodal pathway that project to the basal ganglia (Fig. 11). The ultimate goal of this multisensory integration is the sensory guidance of reaching, saccades, grasping, and pursuit functions attributed to the extrapyramidal system.

The manner this pathway processes sensory information markedly differs from what comes to mind when talking about classical visual processing. It seems that besides the traditional and classical sensory pathways, there is also a multisensory pathway in the mammalian brain that composes an environmental image from visual, auditory, and somatosensory modalities. It seems that this pathway is unique to the feline brain, although some components of it have been described in the canine and ferret brain, too. No similar pathway has been described hitherto in the monkey or in the human brain. An interesting feature of this pathway is that no clear-cut or specific temporal sequence of activation can be observed upon visual stimulation $(24,106)$.

Parallel, largely segregated, closed-loop projections are an important component of cortical-basal ganglia-cortical connectional architecture (64). The basal ganglia are widely regarded as structures involved in sensorimotor integration $(59,98)$. The motor aspects of their function have been extensively analyzed; despite the fact that multisensory information processing appears to be critical for the execution of their role in behavior control, little is known about the sensory background of their function. Electrophysiological, anatomical, and behavioral studies have clarified the roles of both the striatum and the SN in visual

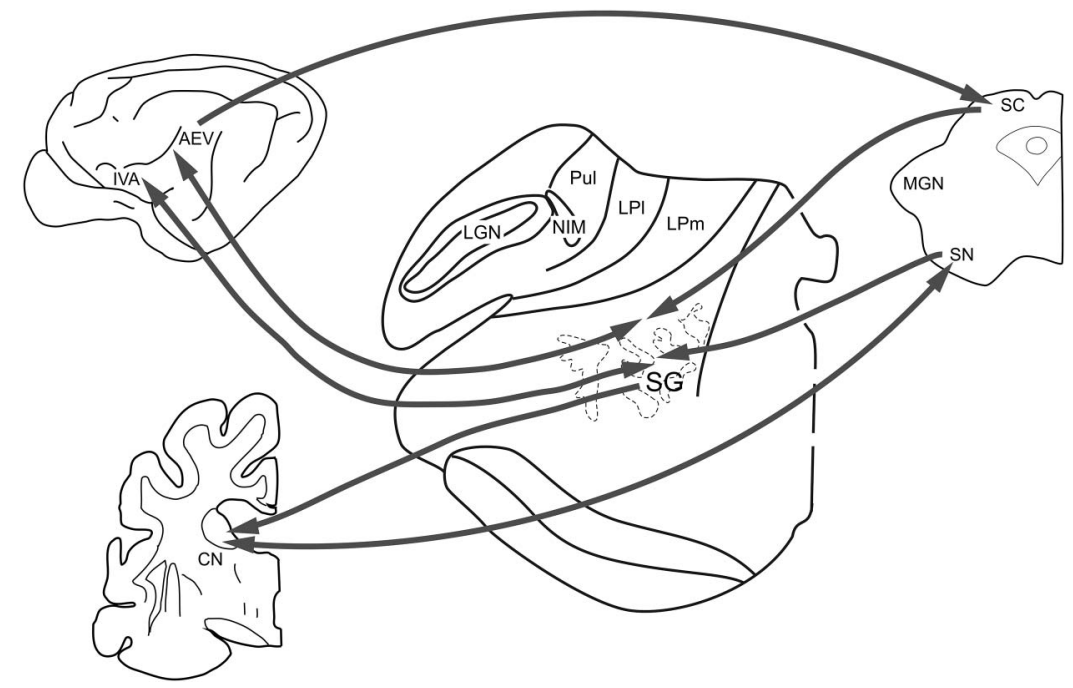

Fig. 11. Connections of the tecto-thalamo-cortico-basal ganglia circuitry. Connections within the tectal visual system are marked with dark arrows. SC: superior colliculus; SN: substantia nigra; SG: suprageniculate nucleus; LGN: lateral geniculate nucleus; Pul: pulvinar; LP: nucleus lateralis posterior; CN: caudate nucleus; IVA: insular visual area; AEV: anterior ectosylvian visual area 
information processing $(16,22,33,34,38,45,62,74,75)$. Data on the representation of other sensory modalities in the basal ganglia are scarcely available. Although some observations have been published on the existence of auditory and somatosensory neurons in the neostriatum $(20,38,86)$ and in the $\mathrm{SN}(39,98,102)$, description of the auditory and somatosensory receptive field properties of the caudate and nigral neurons was still missing. Similarly, little is known about the multisensory receptive field properties of the neurons in the $\mathrm{CN}(20,86)$. Furthermore, we have no information about the neural code of auditory, somatosensory, and multisensory information processing in the $\mathrm{CN}$ and the SN. Does a traditional topographical code exist? Or, similarly to the absence of retinotopy in these two structures $(73,74)$, are they characterized by the absence of topographical coding of auditory and somatosensory stimulus source location? The particular receptive field properties of the caudate and nigral neurons were found to be quite similar to those reported earlier in those thalamic and cortical areas that receive multisensory information from the intermediate and deep layers of the superior colliculus. Thus, a comparison of the receptive field properties in the SN and CN with those of the tecto-thalamo-cortical pathway described earlier could contribute to elucidation of the sensory afferentation of the basal ganglia.

The visual properties of this pathway differ from those described in the geniculo-striate system. The differences include multisensory processing, sensitivity to velocity, directional preference, and the lack of retinotopy. Furthermore, stimulus localization is based not on the merging of the small receptive fields; instead, it seems to be based on panoramic population coding. As the composing structures have important role in practically every action, they could be responsible for automatic movements like saccadic eye movements, pursuit, reaching, and grasping.

The receptive field properties reflect motion sensitivity. The high velocity and directional sensitivity observed in the studied structures is rather uncommon in the geniculo-striate system. Another outstanding property is the extremely large receptive field size, which, together with the lack of orientation sensitivity, indicates that no high-resolution analysis takes place in the structures of the pathway.

AEV lacks global retinotopic organization in its huge receptive fields. Similar large receptive fields have been found upon the exploration of the insular visual area that lies on the rostral, gyral surface of the Sylvian cortex. In addition to the uniformly extensive receptive fields, the Blakemore group described some regular arrangement of neighboring neurons in the "center" of the receptive fields (97). It is interesting in this aspect that Benedek et al. (4) found that the most responsive sites of the receptive fields were located mostly around the area centralis but were dispersed in differing regions, providing the neuronal basis for a possible panoramic coding process. The Wallace group $(52,95)$ approached this question in a bit different way, but they reached a similar conclusion regarding the large receptive fields and panoramic coding in AEV and SN.

The receptive field properties of neurons in the $\mathrm{CN}$ (74) and SN (75) were found to be rather similar to those observed earlier in the SG and in the neurons along the AES. The receptive fields in both structures were extremely large, covered the contralateral and part of the ipsilateral hemifields.

This pathway appears to be unique in its exceptional physiological properties, multimodality, receptive field structures, and the very high velocity and directional sensitivity. Extremely large receptive fields are well known in monkeys, whose inferotemporal cortex, medial superior temporal, and middle temporal area receptive fields are known to include a large portion of the visual fields (66). Nuclei belonging to the accessory optic system of 
monkeys are also reported to have huge receptive fields (40). Guirado et al. (31) described an ascending tectofugal visual system in amniotes.

Summing up our results, we described a neural pathway of the feline brain that processes multimodal tectal information toward the basal ganglia through a thalamo-cortico-thalamic loop (Fig. 11). Our results fit well into the theory published by McHaffie et al. (64) concerning subcortical loops through the basal ganglia. McHaffie's paper describes three parallelly running subcortical loops including the superior colliculus, some midline thalamic nuclei, and the basal ganglia. The reference given in this paper about the participation of midline thalamic structures refers to rat studies (53). The loop described by us concerns the cat's brain and includes SG, which is the target of the cortical neurons along the AES, and most notably that of the insular visual area. The physiological function of the two pathways appears to be completely overlapping. Our report seems to be the first detailed description of receptive field properties of the cortico-thalamo-basal ganglia-cortical pathway in the feline brain. The uncommon receptive field properties might shed light on the function of this pathway including basal ganglia in humans, too.

\section{Acknowledgements}

The authors would like to thank the co-workers of the MPI für Biophysikalische Chemie, Department of Physiology, University of Calgary, Department of Anatomy, University of Niigata, Department of Neurosciences, Wake Forest University, Winston-Salem, Department of Anatomy, University of Sydney, and Department of Physiology, University of Szeged for their contribution to the experiments.

\section{REFERENCES}

1. Abramson BP, Chalupa LM: Multiple pathways from the superior colliculus to the extrageniculate visual thalamus of the cat. J. Comp. Neurol. 271, 397-418 (1988)

2. Alexander GE, Crutcher MD: Functional architecture of basal ganglia circuits: neural substrates of parallel processing. Trends Neurosci. 13, 266-271 (1990)

3. Alexander GE, DeLong MR, Strick PL: Parallel organization of functionally segregated circuits linking basal ganglia and cortex. Annu. Rev. Neurosci. 9, 357-381 (1986)

4. Benedek G, Eördegh G, Chadaide Z, Nagy A: Distributed population coding of multisensory spatial information in the associative cortex. Eur. J. Neurosci. 20, 525-529 (2004)

5. Benedek G, Fischer-Szatmári L, Kovács G, Perény J, Katoh YY: Visual, somatosensory and auditory modality properties along the feline suprageniculate-anterior ectosylvian sulcus/insular pathway. Prog. Brain Res. 112, 324-334 (1996)

6. Benedek G, Hicks TP: The visual insular cortex of the cat: organization, properties and modality specificity. Prog. Brain Res. 75, 271-278 (1988)

7. Benedek G, Jang EK, Hicks TP: Physiological properties of visually responsive neurones in the insular cortex of the cat. Neurosci. Lett. 64, 269-274 (1986)

8. Benedek G, Mucke L, Norita M, Albowitz B, Creutzfeldt OD: Anterior ectosylvian visual area (AEV) of the cat: physiological properties. Prog. Brain Res. 75, 245-255 (1988)

9. Benedek G, Norita M, Creutzfeldt OD: Electrophysiological and anatomical demonstration of an overlapping striate and tectal projection to the lateral posterior-pulvinar complex of the cat. Exp. Brain Res. 52, 157-169 (1983)

10. Benedek G, Pereny J, Kovács G, Fischer-Szatmári L, Katoh YY: Visual, somatosensory, auditory and nociceptive modality properties in the feline suprageniculate nucleus. Neuroscience 78, 179-189 (1997)

11. Benedek G, Sztriha L, Kovács G: Coding of spatial co-ordinates on neurones of the feline visual association cortex. Neuroreport 11, 1381-1384 (2000)

12. Berkley KJ: Response properties of cells in ventrobasal and posterior group nuclei of the cat. J. Neurophysiol. 36, 940-952 (1973) 
13. Berson DM, Graybiel AM: Tectorecipient zone of cat lateral posterior nucleus - evidence that collicular afferents contain acetylcholinesterase. Exp. Brain Res. 84, 478-486 (1991)

14. Bialek W, Rieke F, de Ruyter van Steveninck RR, Warland D: Reading a neural code. Science 252, 1854-1857 (1991)

15. Bignall KE, Imbert N, Buser P: Optic projections of nonvisual cortex of the cat. J. Neurophysiol. 29, 382-395 (1966)

16. Brown VJ, Desimone R, Mishkin M: Responses of cells in the tail of the caudate nucleus during visual discrimination learning. J. Neurophysiol. 74, 1083-1094 (1995)

17. Brugge JF, Reale RA, Jenison RL, Schnupp J: Auditory cortical spatial receptive fields. Audiol. Neurootol. 6, 173-177 (2001)

18. Buser P, Bignall KE: Nonprimary sensory projections on the cat neocortex. Int. Rev. Neurobiol. 10, 111-167 (1967)

19. Chalupa LM, Fish SE: Response characteristics of visual and extravisual neurons in the pulvinar and lateral posterior nuclei of the cat. Exp. Neurol. 61, 96-120 (1978)

20. Chudler EH, Sugiyama K, Dong WK: Multisensory convergence and integration in the neostriatum and globus pallidus of the rat. Brain Res. 674, 33-45 (1995)

21. Clarey JC, Irvine DR: Auditory response properties of neurons in the anterior ectosylvian sulcus of the cat. Brain Res. 386, 12-19 (1986)

22. Clarey JC, Irvine DR: The anterior ectosylvian sulcal auditory field in the cat: I. An electrophysiological study of its relationship to surrounding auditory cortical fields. J. Comp. Neurol. 301, 289-303 (1990)

23. Comoli E, Coizet V, Boyes J, Bolam JP, Canteras NS, Quirk RH, Overton PG, Redgrave P: A direct projection from superior colliculus to substantia nigra for detecting salient visual events. Nature Neurosci. 6, 974-980 (2003)

24. Eördegh G, Nagy A, Berenyi A, Benedek G: Processing of spatial visual information along the pathway between the suprageniculate nucleus and the anterior ectosylvian cortex. Brain Res. Bull. 67, 281-289 (2005)

25. Feger J, Bevan M, Crossman AR: The projections from the parafascicular thalamic nucleus to the subthalamic nucleus and the striatum arise from separate neuronal populations - a comparison with the corticostriatal and corticosubthalamic efferents in a retrograde fluorescent double-labelling study. Neuroscience 60, 125-132 (1994)

26. Georgopoulos AP, Schwartz AB, Kettner RE: Neuronal population coding of movement direction. Science 233, 1416-1419 (1986)

27. Godfraind JM, Meulders M, Veraart C: Visual properties of neurons in pulvinar, nucleus lateralis posterior and nucleus suprageniculatus thalami in the cat. I Qualitative Investigation. Brain Res. 44, 503-526 (1972)

28. Gombkötő P, Rokszin A, Berényi A, Braunitzer G, Utassy G, Benedek G, Nagy A: Neuronal code of spatial visual information in the caudate nucleus. Neuroscience 182, 225-231 (2011)

29. Guillery RW, Feig SL, Van Lieshout DP: Connections of higher order visual relays in the thalamus: a study of corticothalamic pathways in cats. J. Comp. Neurol. 438, 66-85 (2001)

30. Guiloff RD, Lifschitz WS, Ormeño GO, Adrian HA: Visual evoked potentials in cortical auditory and anterior ectosylvian areas of cat. Vision Res. 3, 339-364 (1971)

31. Guirado S, Real MA, Dávila JC: The ascending tectofugal visual system in amniotes: new insights. Brain Res. Bull. 66, 290-296 (2005)

32. Hand PJ, Van Winkle T: The efferent connections of the feline nucleus cuneatus. J. Comp. Neurol. 171, 83-109 (1977)

33. Harting JK, Updyke BV, Van Lieshout DP: Striatal projections from the cat visual thalamus. Eur. J. Neurosci. 14, 893-896 (2001)

34. Harting JK, Updyke BV, Van Lieshout DP: The visual-oculomotor striatum of the cat: functional relationship to the superior colliculus. Exp. Brain Res. 136, 138-142 (2001)

35. Hicks TP, Benedek G, Thurlow GA: Modality specificity of neuronal responses within the cat's insula. J. Neurophysiol. 60, 422-437 (1988)

36. Hicks TP, Benedek G, Thurlow GA: Organization and properties of neurons in a visual area within the insular cortex of the cat. J Neurophysiol. 60, 397-421 (1988)

37. Hicks TP, Watanabe S, Miyake A, Shoumura K: Organization and properties of visually responsive neurons in the suprageniculate nucleus of the cat. Exp. Brain Res. 55, 359-367 (1984)

38. Hikosaka O, Sakamoto M, Usui S: Functional properties of monkey caudate neurons. II. Visual and auditory responses. J Neurophysiol. 61, 799-813 (1989) 
39. Hikosaka O, Wurtz RH: Visual and oculomotor functions of monkey substantia nigra pars reticulata. III. Memory-contingent visual and saccade responses. J Neurophysiol. 49, 1268-1284 (1983)

40. Hoffmann KP, Distler C, Ilg U: Callosal and superior temporal sulcus contributions to receptive field properties in the macaque monkey's nucleus of the optic tract and dorsal terminal nucleus of the accessory optic tract. J. Comp. Neurol. 321, 150-162 (1992)

41. Hollander H, Tietze J, Distel H: An autoradiographic study of the subcortical projections of the rabbit striate cortex in the adult and during postnatal development. J. Comp. Neurol. 184, 783-794 (1971)

42. Huang CC, Lindsley DB: Polysensory responses and sensory interaction in pulvinar and related postero-lateral thalamic nuclei in cat. Electroenceph. Clin. Neurophysiol. 34, 265-280 (1973)

43. Ingram WR, Hannett FI, Ranson SW: The topography of the nuclei of the diencephalon of the cat. J. Comp. Neurol. 55, 333-394 (1932)

44. Jay MF, Sparks DL: Auditory receptive fields in primate superior colliculus shift with changes in eye position. Nature 309, 345-347 (1984)

45. Jiang H, Stein BE, McHaffie JG: Opposing basal ganglia processes shape midbrain visuomotor activity bilaterally. Nature 424, 982-986 (2003)

46. Kadunce DC, Vaughan JW, Wallace MT, Benedek G, Stein BE: Mechanisms of within- and cross-modality suppression in the superior colliculus. J. Neurophysiol. 78, 2834-2847 (1997)

47. Kemp JM, Powell TP: The connexions of the striatum and globus pallidus: synthesis and speculation. Philos. Trans. R. Soc. Lond. B Biol. Sci. 262, 441-457 (1971)

48. Kimura A, Tamai Z: Sensory response of cortical neurons in the anterior ectosylvian sulcus, including the area evoking eye movement. Brain Res. 575, 181-186 (1992)

49. Kita H, Kitai TS: Efferent projections of the subthalamic nucleus in the rat: light and electron microscopic analysis with the PHA-L method. J. Comp. Neurol. 260, 435-452 (1987)

50. Knudsen EI: Auditory and visual maps of space in the optic tectum of the owl. Neuroscience 2, 1177-1194 (1982)

51. Krout KE, Loewy AD, Westby GW, Redgrave P: Superior colliculus projections to midline and intralaminar thalamic nuclei of the rat. J. Comp. Neurol. 431, 198-216 (2001)

52. Krueger J, Royal DW, Fister MC, Wallace MT: Spatial receptive field organization of multisensory neurons and its impact on multisensory interactions. Hear. Res. 258, 47-54 (2009)

53. Krupa M, Maire-Lepoivre E, Imbert M: Visual properties of neurons in the suprageniculate nucleus of the cat. Neurosci. Lett. 51, 13-18 (1984)

54. Lee C, Rohrer WH, Sparks DL: Population coding of saccadic eye movements by neurons in the superior colliculus. Nature 332, 357-360 (1988)

55. Lin CS, May PJ, Hall WC: Nonintralaminar thalamostriatal projections in the gray squirrel (Sciurus carolinensis) and tree shrew (Tupaia glis). J. Comp. Neurol. 230, 33-46 (1984)

56. Linke R, Schwegler H: Convergent and complementary projections of the caudal paralaminar thalamic nuclei to rat temporal and insular cortex. Cereb. Cortex. 10, 753-771 (2000)

57. Lokwan SJ, Overton PG, Berry MS, Clark PG: Stimulation of the pedunculopontine tegmental nucleus in the rat produces burst firing in A9 dopaminergic neurons. Neuroscience 92, 245-254 (1999)

58. Lund RD, Webster KE: Thalamic afferents from the dorsal column nuclei: an experimental anatomical study in the rat. J. Comp. Neurol. 130, 301-312 (1967)

59. Lynd-Balta E, Haber SN: Primate striatonigral projections: a comparison of the sensorimotor-related striatum and the ventral striatum. J. Comp. Neurol. 345, 562-578 (1994)

60. Malinowska M, Kosmal A: Connections of the posterior thalamic region with the auditory ectosylvian cortex in the dog. J. Comp. Neurol. 467, 185-206 (2003)

61. Manger PR, Engler G, Moll CK, Engel AK: The anterior ectosylvian visual area of the ferret: a homologue for an enigmatic visual cortical area of the cat? Eur. J. Neurosci. 22, 706-714 (2005)

62. Márkus Z, Eördegh G, Paróczy Z, Benedek G, Nagy A: Modality distribution of sensory neurons in the feline caudate nucleus and the substantia nigra. Acta Biol. Hung. 59, 269-279 (2008)

63. Mason R: Functional organization in the cat's pulvinar-complex. Exp. Brain Res. 31, 51-66 (1978)

64. McHaffie JG, Stanford TR, Stein BE, Coizet V, Redgrave P: Subcortical loops through the basal ganglia. Trends Neurosci. 28, 401-407 (2005)

65. Medan V, Berón De Astrada M, Scarano F, Tomsic D: A network of visual motion-sensitive neurons for computing object position in an arthropod. J Neurosci. 335, 6654-6666 (2015)

66. Mendoza-Halliday D, Torres S, Martinez-Trujillo JC: Sharp emergence of feature-selective sustained activity along the dorsal visual pathway. Nat. Neurosci. 17, 1255-1262 (2014) 
67. Middlebrooks JC, Clock AE: A panoramic code for sound location by cortical neurons. Science 264, $842-844$ (1994)

68. Middlebrooks JC, Knudsen EI: A neural code for auditory space in the cat's superior colliculus. J. Neurosci. 4, 2621-2634 (1984)

69. Middlebrooks JC, Xu L, Eddins AC, Green DM: Codes for sound-source location in nontonotopic auditory cortex. J. Neurophysiol. 80, 863-882 (1998)

70. Middlebrooks JC, Xu L, Furukawa S, Macpherson EA: Cortical neurones that localize sounds. Neuroscientist 8 , 73-83 (2002)

71. Minciacchi D, Tassinari G, Antonini A: Visual and somatosensory integration in the anterior ectosylvian cortex of the cat. Brain Res. 410, 21-31 (1987)

72. Movshon JA: The velociy tuning of single units in cat striate cortex. J. Physiol. 249, 445-468 (1975)

73. Mucke L, Norita M, Benedek G, Creutzfeldt O: Physiologic and anatomic investigation of a visual cortical area situated in the ventral bank of the anterior ectosylvian sulcus of the cat. Exp. Brain Res. 46, 1-11 (1982)

74. Nagy A, Eördegh G, Norita M, Benedek G: Visual receptive field properties of neurons in the caudate nucleus. Eur. J. Neurosci. 18, 449-452 (2003)

75. Nagy A, Eördegh G, Norita M, Benedek G: Visual receptive field properties of excitatory neurons in the substantia nigra. Neuroscience 130, 513-518 (2005)

76. Nagy A, Eördegh G, Paróczy Z, Márkus Z, Benedek G: Multisensory integration in the basal ganglia. Eur. J. Neurosci. 3, 917-249 (2006)

77. Nalbach H, Thier P, Varju D: Binocular interaction in the optokinetic system of the crab Carcinus maenas (L.): optokinetic gain modified by bilateral image flow. Visual Neurosci. 10, 873-885 (1993)

78. Nicolelis MA, Ghazanfar AA, Stambaugh CR, Oliveira LM, Laubach M, Chapin JK, Nelson RJ, Kaas JH: Simultaneous encoding of tactile information by three primate cortical areas. Nat. Neurosci. 1, 621-630 (1998)

79. Norita M, Hicks TP, Benedek G, Katoh Y: Organization of cortical and subcortical projections to the feline insular visual area, IVA. J. Hirnforsch. 32, 119-134 (1991)

80. Norita M, Mucke L, Benedek G, Albowitz B, Katoh Y, Creutzfeldt OD: Connections of the anterior ectosylvian visual area (AEV). Exp. Brain Res. 62, 225-240 (1986)

81. Olson CR, Graybiel AM: Ectosylvian visual area of the cat: location, retinotopic organization, and connections. J. Comp. Neurol. 261, 277-294 (1987)

82. Olszewski J (1952): The thalamus of the macaca mulatta. An atlas for use in stereotaxic instrument. Karger, Basel

83. Paróczy Z, Nagy A, Márkus Z, Waleszczyk WJ, Wypych M, Benedek G: Spatial and temporal visual properties of single neurons in the suprageniculate nucleus of the thalamus. Neuroscience 137, 1397-1404 (2006)

84. Pinter RB, Harris LR: Temporal and spatial response characteristics of the cat superior colliculus. Brain Res. 207, 73-94 (1981)

85. Poggio GF, Mountcastle VB: A study of the functional contributions of the lemniscal and spinothalamic systems to somatic sensibility. Central nervous mechanisms in pain. Bull. Johns Hopkins Hosp. 106, 266-316 (1960)

86. Pouderoux C, Freton E: Patterns of unit responses to visual stimuli in the cat caudate nucleus under chloralose anesthesia. Neurosci. Lett. 11, 53-58 (1979)

87. Raczkowski D, Rosenquist AC: Connections of the multiple visual cortical areas with the lateral posteriorpulvinar complex and adjacent thalamic nuclei in the cat. J. Neurosci. 3, 1912-1942 (1983)

88. Reale RA, Imig TJ: Tonotopic organization in auditory cortex of the cat. J. Comp. Neurol. 192, 265-291 (1980)

89. Redgrave P, Mitchell IJ, Dean P: Descending projections from the superior colliculus in rat: a study using orthograde transport of heatgermagglutinin conjugated horseradish peroxidase. Brain Res. 15, 795-803 (1987)

90. Rioch DM: Studies on the diencephalon of Carnivora. Part I. The nuclear configuration of thalamus, epithalamus and hypothalamus of the dog and cat. J. Comp. Neurol. 49, 1-119 (1929)

91. Rodriguez M, Abdala P, Obeso JA: Excitatory responses in the direct striatonigral pathway: effect of striatonigral lesions. Mov. Disorders. 15, 795-803 (2000)

92. Rolls ET, Thorpe SJ, Maddison SP: Responses of striatal neurons in the behaving monkey. 1. Head of the caudate nucleus. Behav. Brain Res. 7, 179-210 (1983)

93. Rose JE: The ontogenetic development of the rabbit's diencephalon. J. Comp. Neurol. 77, 61-129 (1942)

94. Rose JE, Woolsey CN (1958): Cortical connections and functional organization of the thalamic auditory system of the cat. In: Biological and Biochemical Bases of Behavior, eds Harlow HF, Woolsey CN, University of Wisconsin Press, Madison, pp. 127-150

95. Royal DW, Carriere BN, Wallace MT: Spatiotemporal architecture of cortical receptive fields and its impact on multisensory interactions. Exp. Brain Res. 98, 127-136 (2009) 
96. Ryugo DK, Killackey HP: Differential telencephalic projections of the medial and ventral divisions of the medial geniculate body of the rat. Brain Res. 82, 173-177 (1974)

97. Scannell JW, Sengpiel F, Tovée MJ, Benson PJ, Blakemore C, Young MP: Visual motion processing in the anterior ectosylvian sulcus of the cat. J. Neurophysiol. 76, 895-907 (1996)

98. Schwarz M, Sontag KH, Wand P: Sensory-motor processing in substantia nigra pars reticulata in conscious cats. J. Physiol. (Lond.) 347, 129-149 (1984)

99. Stein BE: Development and organization of multimodal representation in cat superior colliculus. Fed. Proc. 37 , 2240-2245 (1978)

100. Stein BE, Meredith MA (1993): The Merging of the Senses. MIT Press, Cambridge, MA

101. Stolzberg D, Wong C, Butler BE, Lomber SG: Catlas: an magnetic resonance imaging-based three-dimensional cortical atlas and tissue probability maps for the domestic cat (Felis catus). J. Comp. Neurol. 525, 3190-3206 (2017)

102. Strecker ER: Caudate unit activity in freely moving cats: effects of phasic auditory and visual stimuli. Brain Res. 329, 350-353 (1985)

103. Suzuki H, Kato H: Neurons with visual properties in the posterior group of the thalamic nuclei. Exp. Neurol. 23, 353-365 (1969)

104. Takada M, Itoh K, Yasui Y, Sugimoto T, Mizuno N: Topographical projections from the posterior thalamic regions to the striatum in the cat, with reference to possible tecto-thalamo-striatal connections. Exp. Brain Res. 60, 385-396 (1985)

105. Tamai Y, Miyashita E: Subcortical connections of an "oculomotor" region in the ventral bank of the anterior ectosylvian sulcus in the cat. Neurosci. Res. 7, 249-256 (1989)

106. Theunissen F, Miller JP: Temporal encoding in nervous systems: a rigorous definition. J. Comput. Neurosci. 2 , 149-162 (1995)

107. Tokuno H, Takada M, Ikai Y, Mizuno N: Direct projections from the deep layers of the superior colliculus to the subthalamic nucleus in the rat. Brain Res. 639, 156-160 (1994)

108. Tunturi AR: The pathway from the medial geniculate body to the ectosylvian auditory cortex in the dog. J. Comp. Neurol. 138, 131-136 (1970)

109. Updyke BV: Projections from visual areas of the middle suprasylvian sulcus onto the lateral posterior complex and adjacent thalamic nuclei in cat. J. Comp. Neurol. 201, 477-506 (1981)

110. Vanduffel W, Vandenbussche E, Singer W, Orban GA: Metabolic mapping of visual areas in the behaving cat: a [14C] 2-deoxyglucose study. J. Comp. Neurol. 354, 161-180 (1995)

111. Webster KE: The cortico-striatal projection in the cat. J. Anat. 99, 329-337 (1965) 